\title{
A UTILIZAÇÃO DO ESPAÇO GEOGRÁFICO COMO FERRAMENTA DE ANÁLISE DAS RELAÇÕES SOCIAIS DO CAPITAL
}

\author{
Luiz Antônio da Silva Lima ${ }^{1}$
}

\section{Resumo}

O referido artigo visa discutir as relações sociais, as quais se fazem presentes dentro do espaço geográfico, e a partir disso, transpor quais as principais eventualidades que cercam a atual conjuntura da sociedade, e que, portanto, podem ser estudadas sob uma perspectiva geográfica. Além disso, neste artigo serão analisadas algumas conjunturas históricas que se aplicaram no processo de estruturação da sociedade, as quais atingiram diretamente as dinâmicas do capital social. Realizando um comparativo entre as dinâmicas que cercaram a realidade das sociedades industrial e moderna, o artigo traçou as diferenças encontradas na análise de cada uma, as quais prezaram em decifrar como se davam os processos de troca e dádiva. Ademais, questões que envolvem as dinâmicas das cidades e da divisão do trabalho neste contexto também foram contempladas.

Palavras-chave: Capital Social; Espaço Geográfico; Relações Sociais.

\section{THE USE OF GEOGRAPHIC SPACE AS A TOOL FOR ANALYSIS OF SOCIAL CAPITAL RELATIONS}

\begin{abstract}
This article aims to discuss the social relations that are present within the geographic space, and from that, to transpose the main eventualities that surround the current conjuncture of the society, and that, therefore, can be studied from a geographical perspective. In addition, this article will analyze some historical conjunctures that were applied in the process of structuring the society, which directly affected the dynamics of social capital. Making a comparison between the dynamics that surrounded the reality of industrial and modern societies, the article traced the differences found in the analysis of each one, which took care to decipher how the processes of exchange and donation took place. Furthermore, issues involving the dynamics of cities and the division of labor in this context were also contemplated.
\end{abstract}

Keywords: Social Capital; Geographic space; Social relationships.

\footnotetext{
${ }^{1}$ Licenciado em Geografia pela Universidade de Pernambuco (2019).E-mail: luizantonio1999@gmail.com.
} 


\section{EL USO DEL ESPACIO GEOGRÁFICO COMO HERRAMIENTA DE ANÁLISIS DE LAS RELACIONES SOCIALES DEL CAPITAL}

\section{Resumen}

El artículo referido tiene como objetivo discutir las relaciones sociales, que están presentes dentro del espacio geográfico, y desde allí, transponer cuáles son las principales eventualidades que rodean la coyuntura actual de la sociedad, y que, por lo tanto, pueden estudiarse desde una perspectiva geográfica. Además, este artículo analizará algunas situaciones históricas que se aplicaron en el proceso de estructuración de la sociedad, que afectaron directamente la dinámica del capital social. Al hacer una comparación entre la dinámica que rodeaba la realidad de las sociedades industriales y modernas, el artículo trazó las diferencias encontradas en el análisis de cada una, que se ocupó de descifrar cómo tuvieron lugar los procesos de intercambio y donación. Además, también se abordaron cuestiones relacionadas con la dinámica de las ciudades y la división del trabajo en este contexto.

Palabras clave: Capital social; Espacio geográfico; Relaciones sociales.

\section{INTRODUÇÃO}

Dentro das dinâmicas que estruturam o espaço geográfico, vários fenômenos são ocorrentes, os quais atingem a conjuntura da sociedade constantemente. Estes fenômenos, em geral, são resultados de processos históricos que ocorreram nas mediações deste espaço, e que, influenciam nas dinâmicas até hoje.

$\mathrm{Na}$ atual conjuntura da sociedade, o espaço geográfico possui como principal característica a atuação do sistema capitalista, o qual é palco para diversos fenômenos geográficos, e que atingem as dinâmicas sociais diretamente. Um desses fenômenos são as relações sociais do capital, também compreendidas como capital social.

Apesar das relações de troca e ajudas mútuas serem bastante presentes no contexto da sociedade capitalista, estas dinâmicas começaram a diminuir de intensidade a partir da ocorrência de alguns processos históricos, tais como a Revolução Industrial, a imersão do meio técnico-científico-informacional e também os processos de inovação.

No caso do Brasil, estas relações de cooperação existentes no espaço geográfico, se fazem muito marcantes em sua conjuntura, o que atinge suas esferas públicas e políticas. Além disso, voltando um olhar para as organizações espaciais responsáveis por grande parte da economia das nações, as cidades, no caso dos países subdesenvolvidos, estas possuem características marcantes, tais como a falta de infraestrutura e sobretudo, a aglomeração de centros urbanos. 
Esta realidade que cerca o espaço urbano subdesenvolvido do mundo, influencia diretamente nos sistemas de troca existentes no contexto capitalista, além de serem resultados de uma dinâmica histórica e atingir diretamente os modelos de divisão de trabalho.

Devido à grande intensidade das relações cooperativas no Brasil, alguns autores como Laniado (2001), caracterizam o Estado brasileiro como híbrido, visto que este atua, por um lado, através das regras formais democráticas, e por outro, do mundo informal e suas ramificações.

Através deste entendimento, é possível analisar que todos os fenômenos supracitados possuem um vínculo para com o espaço geográfico. A partir deste pressuposto, os processos que englobam as relações sociais do capital, principal pauta deste artigo, serão analisados através do referido conceito-chave da ciência geográfica.

\section{DINÂMICA HISTÓRICA DO CAPITAL SOCIAL NA SOCIEDADE CAPITALISTA}

\section{Sociedade Industrial}

Dentro do contexto da sociedade capitalista, as interações existentes entre os indivíduos que a constituem servem como base para as relações sociais que se fazem presentes no referido meio. Neste sentido, autores como Laniado (2001) afirmam que a partir destas relações, que fatores como laços e obrigações surgem neste contexto, e que isto é algo positivo, devido a concessão de um sentido à relação de convivência entre indivíduos. Contudo, a partir do surgimento das sociedades industriais, estas relações começaram a se distanciarem, visto que as dinâmicas destas então novas sociedades eram pautadas na produção de objetos e além disso, em seu retorno lucrativo.

Este fato acarretou no afastamento do mundo material para com as relações sociais, o que direcionou ao Estado uma aproximação, consequentemente, das normas legais. A relação do Estado para com as formas legais e informais existentes no espaço pode ser explicada através do exemplo do caso do Brasil, onde há uma grande tradição em relação a estas bases sociais geridas através das relações de troca e reciprocidade. Através deste pressuposto, Laniado (2001, p. 223) aponta que:

A forma ambígua do funcionamento do Estado como um híbrido institucional, que entrecruza, continuamente, o mundo formal das regras democráticas com o mundo informal dos recursos que gravitam em torno das agências públicas e das organizações civis na resolução de conflitos no Brasil. 
A partir do pensamento exposto acima, é possível identificar duas grandes esferas entrelaçadas para com o Estado, sobretudo, dos países subdesenvolvidos como o Brasil, as quais se direcionam para as normas formais e as informais. No que se refere ao contexto do avanço industrial nas sociedades capitalistas, é justamente nas esferas formais que o Estado se aproximará.

Com esta mudança nas dinâmicas da sociedade, consequentemente também diminuíram as relações de solidariedade e confiança, as quais são responsáveis pelo senso de obrigação mútua entre os indivíduos, sendo este o responsável pela base social existente na sociedade.

Corroborando com estes pensamentos, o chamado sistema de dádivas, criado por Mauss (2003), é utilizado por diversos autores, o que enriquece tal discussão. Neste sentido, Salles e Sales (2012, p. 21) apontam que "a tese principal do Ensaio de Mauss (2003) é, portanto, que a vida social se constitui por um constante dar-e-receber. A reflexão mostra ainda como, universalmente, dar e retribuir são obrigações, mas organizadas de modo particular em cada caso".

E além disso, Lanna (2000) apud Salles e Sales (2012, p. 21) reitera:

A dádiva produz aliança, tanto as matrimoniais como as políticas (trocas entre chefes ou diferentes camadas sociais), religiosas (como nos sacrifícios, entendidos como um modo de relacionamento com os deuses), econômicas, jurídicas e diplomáticas (incluindo-se aqui as relações pessoais de hospitalidade).

Tendo em vista os pensamentos acima expostos, é notória a importância das relações de troca dentro do contexto capitalista, visto que através destas, é possível estabelecer relações entre os indivíduos, as quais são essenciais para mover o capital.

Entretanto, no contexto das sociedades industriais, este pressuposto foi se perdendo, afetando as relações entre os sujeitos, prezando a individualidade. Além disso, é a partir deste contexto que as relações de divisão de trabalho também terão uma grande participação na sociedade.

\section{Sociedade Moderna}

Dentro das sociedades modernas, os indivíduos se veem numa realidade onde suas necessidades e ações são movidas pelo consumo desenfreado, o que as maquiam. Devido a isto, vários teóricos tentam compreender estas dinâmicas e como o chamado sistema de dádivas flui dentro deste contexto. 
A principal característica da dinâmica moderna é a monopolização do capitalismo, o qual sofre diretamente a influência de um paradigma, o chamado neoliberalismo, e que além desta nomenclatura, lhe são atribuídas várias outras. Neste sentido, segundo Godbout (1998) apud Salles e Sales (2012, p. 24)

As diversas nomenclaturas atribuídas ao paradigma, podem classificar seus diferentes aspectos, porém existe um ponto em comum em todos eles que pode resumir sua essência: "procura explicar o sistema de produção e, sobretudo, de circulação das coisas e dos serviços na sociedade a partir das noções de interesse, de racionalidade, de utilidade".

Através deste pensamento, é possível fazer uma alusão às relações sociais citadas anteriormente. Como mencionado, estas, as quais se configuram de forma geral como relações de troca, são fundamentais para a formulação das relações entre os indivíduos, porém foram se modificando durante os anos.

No caso das sociedades modernas, estas relações estão muito mais associadas à liberdade do que às obrigações ${ }^{2}$. Esta liberdade mencionada se refere ao livre acesso a mercadorias, livre mercado e entre outros fatores, os quais não possuem regras, muito menos obrigações sociais.

Além disso, vale ressaltar que na conjuntura moderna das sociedades, as suas atividades dão aos indivíduos várias possibilidades de projeções futuras, as quais incluem estas relações de troca, assim como aponta Laniado (2001, p. 225):

As atividades modernas tornam os indivíduos mais interdependentes para a realização das condições objetivas de vida, diversificando mais as funções individuais, as posições ocupadas e, em última instância, multiplicando as modalidades de vínculos nos diferentes ambientes dos quais os indivíduos participam.

Estes fatores apontados na citação de Laniado (2001) possuem influência da divisão do trabalho imposta na sociedade, a qual permitirá ao indivíduo projetar seus objetivos, além de permitir frequentar diferentes ambientes.

Contudo, Laniado (2001, p. 225) reitera:

\footnotetext{
${ }^{2}$ Segundo autores como Lundvall (2001) e Laniado (2001), a noção de obrigação no contexto da sociedade capitalista está vinculada a ideia de troca de favores, onde quando um determinado indivíduo oferece a outro uma prestação de serviço, moralmente, o indivíduo que recebeu esta prestação terá a obrigação de futuramente retribuir.
} 
O que varia em tantas modalidades de existência é influenciado pela personalidade social que se forma e pela cultura. Portanto, as experiências de liberdade e obrigação não se constituem como referenciais absolutos (idênticos para todos) das relações e condutas humanas, mas são sempre relativas a cada experiência em determinada sociedade.

A partir desta concepção, percebe-se que a liberdade e a obrigação, fatores provenientes das relações sociais, não se aplicam de forma unânime em todo o espaço geográfico. Estas relações variam de acordo com as dinâmicas existentes em uma determinada sociedade, além da cultura dela.

Como antes mencionado, a dinâmica da sociedade moderna é a influência recebida plos moldes do capital, o qual se deixa levar pelo paradigma do neoliberalismo. Dentro deste paradigma é possível encontrar uma grande liberdade no que se refere ao mercado. Neste sentido, Berthoud (1993, p. 53) apud Salles e Sales (2012, p. 24) classifica o mercado como um meio criado pela sociedade moderna, onde os indivíduos buscam sanar as dívidas pontualmente, sem que haja comprometimentos futuros.

Esta liberdade no que se refere ao consumo e as necessidades moldadas pelo capital dentro das sociedades modernas podem ser consideradas como as atuais relações sociais dentro das suas conjunturas, visto que, como mencionado por Berthoud (1993), os indivíduos possuem um objetivo de não se prenderem a obrigações futuras.

Este dilema vivido pelos indivíduos das sociedades modernas é influenciado muitas vezes pelo capital, contudo, de certa forma, estes possuem mais liberdade para projetar seus objetivos, sem se preocupar com futuras ligações.

O sistema de dádivas, proposto por Mauss (2003), por sua vez, aponta que as relações sociais estabelecidas entre os indivíduos variam de acordo com a sua livre escolha. Por outro lado, a dádiva não varia de acordo com as questões mercantis, visto que os agentes sociais não são influenciados por equivalências e dívidas.

No contexto econômico, a dádiva possui como objetivo evoluir os pensamentos de uma determinada sociedade, a fim de manter uma homogeneização no que se refere a concepção de um bem comum, o que foge, portanto, do individualismo. Corroborando com este pensamento, Salles e Sales (2012, p. 27) afirmam que:

A dádiva é sistema que propicia o vínculo pela comunicação, atua para romper o isolamento e para que as pessoas sintam sua própria identidade. Por isso é perceptível o sentimento de poder, de transformação, de abertura, de vitalidade que invade os doadores, que dizem que recebem mais do que dão. 
Vale ressaltar que a dádiva se sobressai ao padrão das dinâmicas da sociedade, onde se preza o seguimento de normas e regras, pois, na dádiva, o que possui maior relevância é a boa sensação estabelecida numa relação entre indivíduos. Além disso, através da inserção da dádiva nas sociedades modernas, o sentimento de cooperação e ajuda comunitária originou algumas comunidades que se destacam por suas atuações.

\section{As comunidades cooperativas na sociedade moderna}

Estas comunidades, as quais são exceções dentro do sistema capitalista, agem voluntaria ou involuntariamente visando aproximar os indivíduos através de relações comunitárias, constituindo alianças que se vinculam à ideia de cooperação. A partir desta compreensão, é possível notar que é neste sentido que o capital social se faz presente.

Como antes mencionado, nas sociedades modernas, as quais são diretamente ligadas as dinâmicas capitalistas, os vínculos estabelecidos entre os indivíduos se caracterizam a partir das relações de troca, onde se estabelece uma determinada obrigação de reciprocidade entre eles. No caso destas comunidades, a dinâmica econômica é diferenciada, visto que as ações são executadas sem expectativas de reciprocidade.

Em relação a esta forma diferenciada da economia que se vincula ao capital social, Santos (2003, p.40) afirma que:

De fato, o capital social se comporta de forma relativamente diferente das outras formas de capital. Diferentemente do capital físico, o capital social parece se beneficiar e acumular com o uso, de certa forma se assemelhando ao capital humano. Mas, diferente deste último, que tem um benefício pessoal bastante tangível e claro (investimento em estudo formal, por exemplo, está diretamente ligado com empregos nos quais um indivíduo poderia trabalhar e uma expectativa de renda resultante disso), o capital social tem nítidas características de um bem público.

Através deste pressuposto, é possível afirmar que o capital social é um tipo de capital diferenciado, em relação ao capital físico, o qual visa relações lucrativas. O capital social, por sua vez, está ligado diretamente em relações solidárias que visam um bem comum, as quais são desligadas da ideia de reciprocidade. Além disso, as chamadas economias de dádiva, podem ser comparadas a economias primitivas e até para com as planificadas. 


\section{AS CIDADES E SUA INFLUÊNCIA NO ESPAÇO GEOGRÁFICO}

\section{As cidades dos países subdesenvolvidos}

Para melhor compreensão das relações existentes na esfera do capital social, é preciso que se entenda como estas se aplicam no âmbito das cidades, visto que estas podem ser consideradas como organizações espaciais que possuem grande relevância nas dinâmicas econômicas de uma determinada nação. Com isso, pode-se entender que nas cidades, estas relações ficam mais evidentes dentro do espaço geográfico.

Contudo, o processo de urbanização não se deu de forma homogênea em todo o mundo. Como antes mencionado, o Brasil, em sua conjuntura, possui uma certa tradição no que se refere às relações de troca, e para compreendê-las através de uma análise vinculada ao espaço urbano, é preciso olhar as cidades dos países subdesenvolvidos.

Como mencionado, o espaço urbano sofreu diversos processos para sua estruturação, e as principais diferenças estão vinculadas às características das cidades de países periféricos e centrais (desenvolvidos). Em relação ao processo de urbanização dos países, Fonseca (2016, p. 11) explica que:

Nos países desenvolvidos, o processo de urbanização acompanhou o processo de industrialização nas diferentes etapas e foi evoluindo gradativamente. Nos países subdesenvolvidos ou em desenvolvimento, a urbanização também acompanhou o ritmo da industrialização, mas este processo aconteceu de forma desordenada, não permitindo que os espaços urbanos se preparassem para receber os fluxos migratórios.

Através do pensamento de Fonseca (2016), é possível identificar que a industrialização foi um dos grandes fatores que permitiram o surgimento e desenvolvimento das cidades, contudo, este fator foi inserido na constituição urbana dos países de diversas formas, sendo nos países desenvolvidos, de forma gradativa, e nos periféricos, de forma desordenada. Todavia, as divergências existentes entre as cidades periféricas e centrais não se resumem a isto.

No caso dos centros urbanos dos países subdesenvolvidos, a característica destas organizações espaciais que é explicitada de forma mais evidente é a falta de infraestrutura. Entretanto, Fernandes (2016) ainda aponta outra característica: o investimento concentrado em alguns poucos centros urbanos nestes países, geralmente em capitais nacionais. 
Estas características se aplicam, sobretudo, em países da América Latina e Caribe, onde se aglomeram grande parte dos países subdesenvolvidos industrializados, e que possuem grande parte da população em áreas urbanas.

No caso do Brasil, esta aglomeração de investimentos em cidades como São Paulo e Rio de Janeiro, ainda evidencia a herança colonial que o país possui, representado por uma economia dispersa no território nacional, sem apresentar uma economia nacionalmente integrada.

A partir do entendimento em relação às cidades dos países subdesenvolvidos, podemos analisar melhor como o espaço urbano se dinamiza de uma forma geral. Como mencionado, as cidades são organizações espaciais que possuem grande influência na economia de um determinado território, a qual se aplica através da oferta de bens e serviços.

A partir dessa oferta, podemos observar que é no espaço urbano que fica mais evidente as dinâmicas das relações de troca dentro da sociedade capitalista. Através de linhas gerais, Fernandes (2016) aponta que em sua conjuntura, as cidades possuem influencia em áreas onde o padrão de desenvolvimento é menor, tais como as aldeias, as áreas rurais. Sendo assim, entende-se que sem a existência das cidades, alguns fenômenos não existiriam, além de ações movidas pela objetivação do lucro, tais como o manejo de recursos naturais.

\section{A DIVISÃO DO TRABALHO E AS RELAÇÕES DE TROCA}

Através desta concepção, é induzida a compreensão de que a influência das cidades se dá através da divisão do trabalho. Para autores como Adam Smith (1776) apud Fernandes (2016), a divisão do trabalho pode ser entendida como um gatilho para os processos econômicos. Em relação a periodização das divisões de trabalho, estas já existiam em sociedades anteriores, assim como mostra Laniado (2001, p. 225) ao afirmar que "o mundo industrial está fundamentado em extensas formas de interdependência a partir da divisão do trabalho, aquilo que a análise durkheimiana caracterizou como base para a solidariedade orgânica".

Como antes mencionado, as cidades possuem grande influência sobre o espaço geográfico. Contudo, vale ressaltar que sua influência é tão expressiva ao ponto de induzir até na divisão de trabalho rural.

Além disso, as cidades possuem uma grande aglomeração de indivíduos, superior às demais localidades do espaço geográfico. Esta aglomeração, por sua vez, favorece o estímulo de relações de troca e consolida as dinâmicas do mercado. Segundo Fernandes (2016), o 
crescimento das cidades está diretamente ligado à proximidade das pessoas, onde a partir deste fenômeno, novos trabalhos surgirão. É neste sentido que as cidades crescem, não por produzir mais o que já produziam, mas pelo surgimento de novos trabalhos.

Através desta concepção, é possível fazer uma alusão às políticas de inovação, as quais se fazem presentes no contexto das sociedades modernas, e se evidenciam dentro do âmbito das cidades. Neste sentido, Lundvall (2001, p. 200) afirma que "o objetivo principal da política de inovação deve ser contribuir para a capacitação de empresas, de instituições voltadas para o conhecimento e da população em geral”.

Ainda através do pensamento do referido autor, podemos associar estas políticas inovação e aprendizado que surgem dentro das sociedades modernas, para com as relações do capital social. Segundo Lundvall (2001, p. 204), o capital social poderia se constituir possíveis empecilhos para o desenvolvimento das políticas de inovação:

A presença e a forma do "capital social", num contexto mais amplo, afetarão o processo de aprendizagem. Numa sociedade extremamente individualista ou na qual a lealdade está estreitamente relacionada com uma família, a aprendizagem partilhada pode tornar-se muito difícil.

A partir dos entendimentos tratados até então, é possível notar que as cidades constituem as organizações espaciais que possuem maior concentração de indivíduos, e através disso, as interações entre eles são mais intensas, onde adquirem como principal norteador a divisão do trabalho, resultando nas relações de troca, corriqueiras nas atividades do capital.

\section{AS RELAÇÕES DE TROCA, A LIBERDADE E A OBRIGAÇÃO NO CONTEXTO DAS SOCIEDADES INDUSTRIAL E MODERNA}

Dentro dos estudos da ciência geográfica, vários conceitos são estudados, e estes variam em seus aprofundamentos. Como se sabe, o espaço geográfico é o principal objeto de estudo da Geografia, o qual foi conceituado por Santos (1978) apud Saquet e Silva (2008, p. 7) da seguinte forma:

O conceito de espaço é central e compreendido como um conjunto de formas representativas de relações sociais do passado e do presente e por uma estrutura representada por relações que estão acontecendo e manifestam-se através de processos e funções.

Corroborando com esta conceituação, é possível destacar que as relações sociais estão totalmente presentes no espaço geográfico, sendo este o principal palco dos fenômenos destrinchados ao longo deste artigo. 
Ainda através do pensamento de Santos (1978), o espaço geográfico ainda carrega heranças do passado, as quais vão refletir no presente e futuro, e que vão estruturar as relações existentes dentro de uma determinada sociedade.

Esta variação histórica está vinculada a percepção de Laniado (2001), onde afirma que os sentimentos de liberdade e obrigação, intrínsecos ao ser humano dentro das relações de troca, variam de acordo com a forma em que uma sociedade foi estruturada, além da sua cultura também.

Devido a este fato foram analisadas as dinâmicas das sociedades capitalistas numa alusão entre os períodos de industrialização e modernidade, e suas inter-relações para com as relações sociais de troca ${ }^{3}$. A priori, assim como destacado na Figura 1, vemos fatos ligados a estas dinâmicas.

Ademais, a sociedade industrial se estrutura de forma voltada à produção, e isso gera um distanciamento das relações sociais entre os indivíduos, o que gera um índice muito baixo de relações de troca. Entretanto, mesmo com estes pequenos índices, elas ainda acontecem. Quando este processo ocorre, os indivíduos da sociedade industrial sentem de forma muito mais forte o sentimento de obrigação do que os da sociedade moderna. Já no que se refere a liberdade, estes não possuem grandes projeções futuras, pois não possuem grandes arbítrios econômicos, o que gera também um pequeno índice deste fator.

Figura 1. Características das relações sociais nas sociedades industrial e moderna

\begin{tabular}{|c|c|}
\hline $\begin{array}{l}\text { SOCIEDADE } \\
\text { INDUSTRIAL }\end{array}$ & $\begin{array}{l}\text { SOCIEDADE } \\
\text { MODERNA }\end{array}$ \\
\hline $\begin{array}{l}>\text { Dinâmica voltada a } \\
\text { produção; } \\
>\quad \begin{array}{l}\text { Distanciamento das } \\
\text { relações sociais. }\end{array}\end{array}$ & $\begin{aligned} & \text { capitalismo; } \\
&>\quad \text { Neoliberalismo; } \\
&> \text { Liberdade em } \\
& \text { evidencia. }\end{aligned}$ \\
\hline
\end{tabular}

Fonte: O autor (2020).

A partir do esquema mostrado na figura 1, vemos que enquanto na sociedade industrial as relações sociais se distanciam por conta da atenção voltada à produção, nas sociedades modernas teremos relações sociais estabelecidas através de uma grande influência do capital.

\footnotetext{
${ }^{3}$ As relações sociais de troca englobam fatores que vão desde as trocas de favores entre indivíduos até negociações econômicas entre empresas, as quais podem resultar na noção moral de obrigação.
} 
A utilização do espaço geográfico como ferramenta de análise das relações sociais do capital

Através desta análise, consegue-se compreender como se dá a fluidez do capital nestes diferentes contextos de sociedade. Analisando a tabela 1, vemos de forma esquemática como as dinâmicas explicitadas na figura 1 resultam na forma em que as relações de troca, liberdade e obrigação se aplicam no espaço geográfico.

Tabela 1. Proporções entre relações de troca, liberdade e obrigação.

\begin{tabular}{|c|c|c|}
\hline & SOCIEDADE MODERNA & SOCIEDADE INDUSTRIAL \\
\hline Relações de troca & & \\
\hline Liberdade & & \\
\hline Obrigação & & \\
\hline
\end{tabular}

Fonte: o autor (2020).

Através da análise da tabela 1, podemos identificar que as relações de troca entre os indivíduos crescem em relação ao contexto das sociedades modernas. Contudo, assim como aponta Berthoud (1993), apesar destas relações gerarem um amento no sentimento de obrigação entre os indivíduos, no contexto moderno, estes estão tendo mais liberdade para projetar seus objetivos futuros, o que inclui o desprendimento das obrigações.

Assim como mostrado anteriormente através do pensamento de Santos (1978), o espaço geográfico é um grande palco para vários fenômenos. As relações sociais, principal pauta deste artigo, são provenientes da interação entre indivíduos dentro do espaço geográfico. Para melhor análise destas questões, é importante que se olhe para organizações espaciais onde estas relações sejam bastante evidentes, como é o caso das cidades.

Como mencionado, as cidades são organizações espaciais onde há uma expressiva aglomeração de indivíduos, e é isto que permite o surgimento das relações sociais, as quais dão sentido à vida em comunidade. Contudo, o processo de urbanização se deu de diversas formas sobre o espaço geográfico, assim como apontado na figura 2. 
Figura 2. A influência das cidades no espaço e os diferentes processos de urbanização

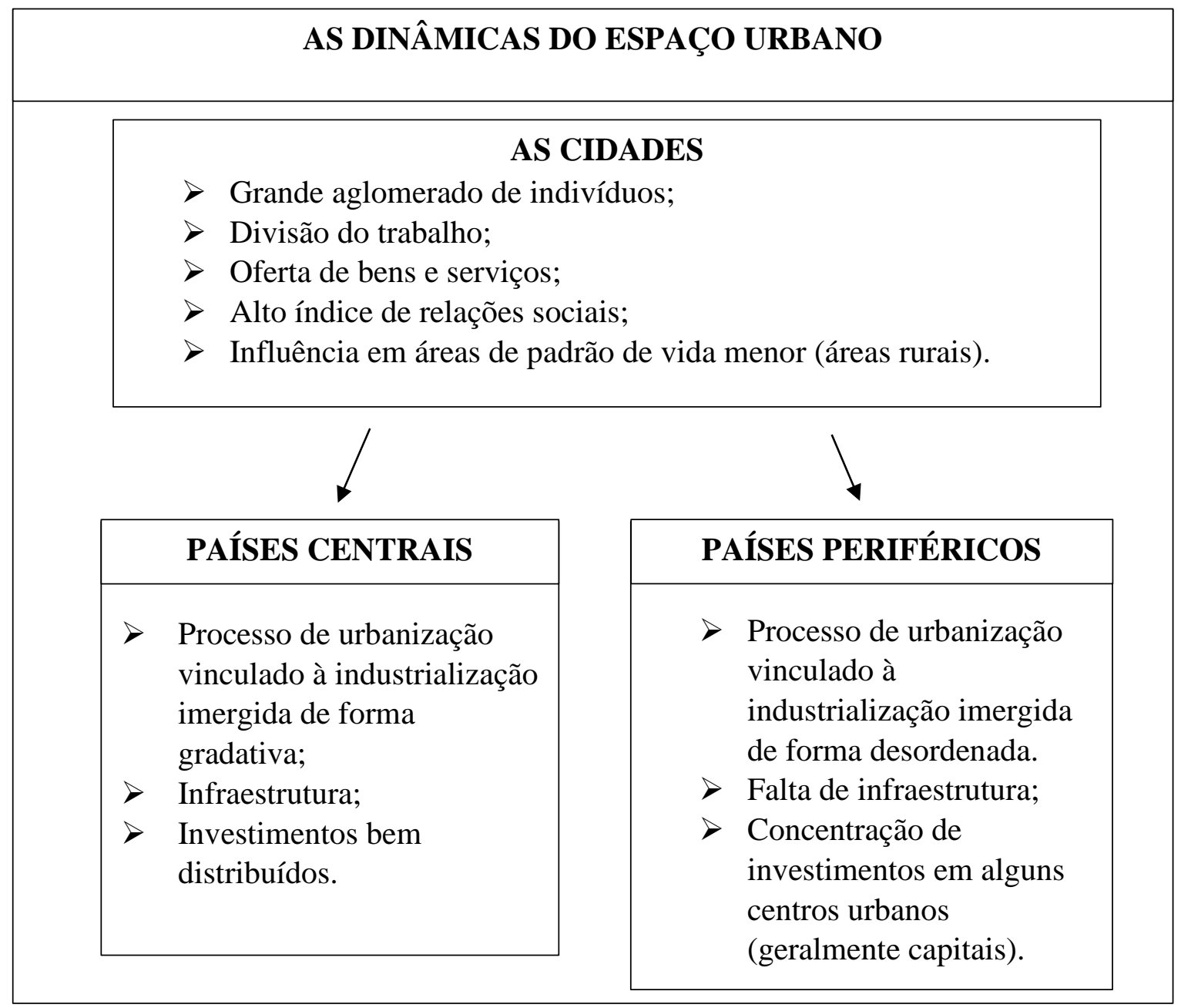

Fonte: o autor (2020).

Através da esquematização trazida acima pela Figura 2, vemos dinamicamente algumas das principais características do comportamento das cidades e como elas influenciam no espaço geográfico. Além disso, partindo do pressuposto trazido por Santos (1978), onde ele aponta que o espaço geográfico é resultado de processos do passado, os quais vão reverberar no presente e futuro, a referida figura traz alguns processos os quais as cidades dos países periféricos e centrais sofreram durante sua estruturação.

Vale ressaltar que através desta exposição, é possível corroborar para com a concepção de Laniado (2001), onde afirma que as relações sociais possuem diversas formas de aplicação dentro do espaço geográfico, onde vão variar de acordo com a forma em que as sociedades foram estruturadas. A partir da analogia feita na figura 2, vemos que, no caso do processo de urbanização, temos diferentes formas de estruturação. 
No que se refere a este processo, autores como Correa (1989, p. 11) apontam que "o espaço urbano capitalista é um produto social, resultado de ações acumuladas através do tempo, e engendradas por agentes que produzem e consomem espaço". Corroborando com este pensamento, é possível evidenciar que a conjuntura do espaço urbano engloba em si resultados das ações que nele se aplicam. Estas ações, por sua vez, também incluem as relações sociais de troca, a liberdade econômica e a sensação intrínseca de obrigação.

Um dos fatores que estão presentes na estrutura das cidades e que possuem grande relevância nas suas dinâmicas, é a divisão do trabalho. Segundo autores como Fernandes (2016), este processo é o responsável por estabelecer a forma em que se aplicará as relações sociais entre os indivíduos e também entre o mundo desenvolvido e subdesenvolvido, assim como aponta Servilha (2008, p. 22), quando afirma que "a divisão de trabalho, presente nas relações sociais muito antes do sistema capitalista no Ocidente, provoca consequentemente e inevitavelmente, as relações de troca".

Este pensamento confirma a imagética de Laniado (2001), principalmente no que se trata das sociedades industriais. Como analisado, estas sociedades apresentavam uma conjuntura que englobava divisões de trabalho totalmente voltadas à produção industrial, e a partir disso, as relações sociais se distanciaram. Já no mundo moderno, vemos uma divisão de trabalho voltada à informação, mídia e entre outros, onde se faz necessário o estabelecimento de grandes relações sociais, o que de fato ocorre neste contexto. Isso comprova, portanto, a grande influência existente da divisão do trabalho para com as relações sociais que ocorrem no espaço geográfico.

\section{CONSIDERAÇÕES FINAIS}

Através da abordagem feita ao longo deste artigo, é possível compreender que para a análise de fenômenos geográficos, é importante que haja uma averiguação no que se refere a atuação destes sobre o espaço geográfico. O principal objeto de estudo da ciência geográfica, por sua vez, se torna o principal palco das interações humanas para com o meio, e é a partir destas interações que surgem os fenômenos, e para analisa-los, é preciso ter noção do que o espeço geográfico representa.

A principal temática abordada no presente artigo foi a questão das relações sociais do capital, as quais podem ser intituladas de "capital social", "economia de dádiva" e até "capital humano", e que englobam fatos intrínsecos ao ser humano, tais como a liberdade e a obrigação. 
Contudo, se levarmos para uma análise sob um olhar voltado ao espaço geográfico, estes fenômenos conseguem ser melhor explicados.

Como mencionado, o espaço geográfico não é algo imediato, mas sim um resultado de várias interações e processos do passado, os quais vão se acumulando e formando subsídios para as futuras interações e as atuais. Estes processos, todavia, não se aplicam de forma homogênea em todo o espaço geográfico. Através deste pressuposto, no que se refere às relações sociais do capital, este artigo resultou numa análise de como estas se comportaram durante os períodos históricos, mas também como se dão sobre o espaço geográfico.

Em relação às periodizações históricas, foi possível identificar que em épocas onde haviam as chamadas "sociedades industriais", as relações sociais estabelecidas entre os indivíduos começaram a se distanciar, visto que havia uma mecanização não só na divisão do trabalho, mas também nas atitudes das pessoas. Os indivíduos, nesta época, estavam totalmente voltados para a produção, enquanto o princípio de vivência em comunidade estava se perdendo.

No posterior grande período histórico destacado ao longo deste artigo, o período das sociedades modernas, as relações sociais estão totalmente vinculadas às dinâmicas do capitalismo (o qual sofre influência do paradigma do neoliberalismo), e estão muito mais ligadas, sobretudo, à noção de liberdade do que à obrigação.

Isso se explica pelo fato de que neste contexto, os indivíduos estão mais livres para projetar seus objetivos, e para que isto ocorra sem percalços, subentende-se que não haja obrigações para com ninguém. Basicamente, estas relações estão vinculadas a ideia de quitação de dívidas.

Através deste pressuposto, é possível analisar que o capital físico ganhou um grande espaço dentro das sociedades modernas. Contudo, o capital social ainda resiste dentro deste âmbito, através de comunidades, onde as relações de troca não se vinculam a ideia de reciprocidade, e sim de solidariedade.

Até então, por meio desta concepção de como o fenômeno do capital social se aplica em contextos históricos distintos, vemos que o viés ideológico de que o espaço geográfico é resultado de processos históricos que se acumulam, fica mais evidente. A posteriori, o artigo visou analisar as cidades e sua influência dentro do espaço geográfico, sobretudo, no que se refere ao fenômeno estudado. Este viés foi tomado, para que ficasse explícita as diferentes aplicações de um determinado fenômeno sobre o espaço geográfico.

Através desta análise, resultou-se na compreensão da evidência das diferentes aplicações. As cidades, onde há uma grande aglomeração de indivíduos, sofreram processos 
diferenciados em sua estruturação, sobretudo entre países desenvolvidos e periféricos. As diferenças encontradas nestas duas situações evidenciam as diferentes aplicações de um fenômeno dentro do espaço geográfico.

Em suma, a análise e compreensão dos fenômenos que ocorrem para com o meio, para serem melhor abordados, é importante concernir as dinâmicas do espaço geográfico, tanto no que se refere as suas periodizações temporais, quanto suas variações, o que, portanto, mostra que o conceito-chave da geografia serve para enriquecer uma inspeção de um determinado fenômeno, tais como as relações sociais do capital, trabalhadas ao longo deste artigo.

\section{REFERÊNCIAS BIBLIOGRÁFICAS}

CORREA, Roberto Lobato. O Espaço Urbano. 1 ed. São Paulo: Editora Ática S.A, 1989.

FERNANDES, Ana Cristina. Sistema territorial de inovação ou uma dimensão de análise na geografia contemporânea. In: SPOSITO, Eliseu (org.). A diversidade da Geografia brasileira. Escalas e dimensões de análise e da ação. Rio de Janeiro: Consequência Editora, 2016. p. 113.143.

FONSECA, Lorena de Oliveira. Urbanização e variação climática na região Nordeste do Brasil. 2016. Dissertação (Mestrado em Economia) - Programa de Pós-Graduação em Economia, UFBA, Salvador - BA.

LANIADO, Ruthy Nadia. Troca e reciprocidade no campo da cultura política. Universidade Federal da Bahia. Salvador, 2001, pp. $222-243$.

LUNDVALL, Bengt-Ake. Políticas de Inovação na Economia do Aprendizado. Parcerias Estratégicas, n. 10, p. 200 - 218, mar. 2001.

SALLES, Maria do Rosário Rolfsen; SALES, Gabriela Arantes Ferreira de. O Sistema de dádiva nas relações comunitárias e a constituição de alianças pelo trabalho tradicional. In: Cultur, Ilhéus (BA), ano $06-\mathrm{n}^{\circ} 02-\mathrm{Jun} / 2012$, pp. $20-41$.

SANTOS, Fábio Franklin Storino dos. Capital Social: Vários conceitos, um só problema. 2003. Dissertação (Mestrado em Administração Pública e Governo) - Programa de Pósgraduação em Administração Pública e Governo, Fundação Getúlio Vargas. São Paulo - SP.

SAQUET, Marcos Aurelio; SILVA, Sueli Santos. MILTON SANTOS: concepções de geografia, espaço e território. Geo UERJ, n. 18, p. 24 - 42, jul. 2008.

SERVILHA, Mateus de Moraes. As relações de trocas materiais e simbólicas no mercado municipal de Araçuaí - MG. 2008. Dissertação (Mestrado em Extensão Rural) - Programa de Pós-graduação em Extensão Rural, UFV, Viçosa - MG.

Recebido em 23 de maio de 2020

Aceito em 01 de fevereiro de 2021

Publicado em 07 de maio de 2021 